\title{
Karakteristik Ideal pada Seminear-Ring dan Seminear-Ring Sederhana
}

Meryta Febrilian Fatimah ${ }^{1}$, Ahmad Ansar ${ }^{2}$

Program Studi Matematika, Fakultas Matematika dan Ilmu Pengetahuan Alam, Universitas

Sulawesi Barat, Majene, Indonesia ${ }^{1,2}$

Email: merytaff@unsulbar.ac.id ${ }^{1}$, ahmad.ansar@unsulbar.ac.id ${ }^{2}$

\begin{abstract}
Abstrak. Penelitian ini adalah penelitian pengembangan dari hasil generalisasi semiring dan near-ring yang disebut seminear-ring. Diberikan seminear-ring $S$. Ideal pada seminear-ring $S$ didefinisikan dengan cara yang sama seperti ideal pada semiring. Oleh karena itu, akan diidentifikasi beberapa jenis ideal dan sifat-sifatnya pada $S$ yaitu ideal prima, ideal semiprima, ideal prima lengkap dan ideal semiprima lengkap. Selanjutnya, Ideal kiri (kanan) $S a(a S)=S$ berakibat $S$ seminear-ring sederhana kiri (kanan). Lebih lanjut untuk $(S a) S=S$ maka $S$ merupakan seminear-ring sederhana. Konsep ideal pada seminear-ring akan diperkenalkan lebih khusus pada penelitian ini.
\end{abstract}

Kata Kunci: Seminear-Ring, Ideal Prima, Ideal Semiprima, Seminear-Ring Sederhana.

\begin{abstract}
This paper is a research and development which aims to generalize semiring and near-ring called seminear-ring. Let $S$ be a seminear-ring. Ideal on seminear-ring $S$ is defined equally to ideal on semiring. The purpose of this paper is to identify some property of Ideal in $S$, namely prime ideal, semiprime ideal, completely prime ideal, and completely semiprime ideal. Furthermore, any left (right) ideal $S a(a S)=S$ constructed $S$ as left (right) simple seminear-ring. Moreover, if $(S a) S=S$, then $S$ is simple. Ideal concept on seminear-ring is given.
\end{abstract}

Keywords: ～Seminear-Ring, Prime Ideal, Semiprime Ideal, Simple Seminear-Ring.

\section{A. Pendahuluan}

Ring adalah sebuah himpunan tak kosong $R$ yang dilengkapi dengan dua operasi biner penjumlahan $(+)$ dan perkalian $(\cdot)$ dengan syarat $R$ terhadap operasi penjumlahan merupakan grup komutatif, terhadap operasi perkalian merupakan semigrup serta terhadap operasi penjumlahan dan perkalian memenuhi hukum distributif kiri dan kanan yaitu untuk setiap $a, b, c \in R$ berlaku $a(b+c)=a b+a c$ dan $(a+b) c=a c+b c$ (Dummit \& Foote, 2004). Ring $R$ dengan tambahan sifat komutatif terhadap operasi perkalian disebut dengan ring komutatif. Selanjutnya apabila ring komutatif $R$ dengan elemen satuan di mana setiap elemen tak nol di $R$ memiliki invers terhadap operasi perkaliannya disebut dengan lapangan (Malik, Mordeson, \& Sen, 1997). Dengan demikian, ring $R$ dengan elemen satuan yang diperlemah yaitu dengan menghilangkan eksistensi elemen invers terhadap operasi penjumlahan membentuk struktur baru yang disebut dengan semiring dan dinotasikan dengan $(S,+, \cdot)$ (Golan, 2013). Beberapa hasil pada ring dapat ditemukan pada semiring, namun sebaliknya belum tentu berlaku. Seperti ideal subtraktif atau $k$-ideal pada semiring yang tidak dapat ditemukan definisinya pada ring (Atani, 2013). Sehingga dapat diketahui bahwa setiap ring $R$ merupakan semiring, tetapi tidak berlaku sebaliknya.

Selanjutnya, near-ring adalah himpunan tak kosong $N$ yang dilengkapi dengan dua operasi biner penjumlahan $(+)$ dan perkalian $(\cdot)$ di mana $N$ terhadap operasi penjumlahannya grup (tidak harus abelian), $N$ terhadap operasi perkaliannya juga semigrup serta $N$ terhadap kedua operasi penjumlahan dan perkaliannya memenuhi hukum distributif kanan (Pilz, 1983). Berdasarkan hasil yang diperoleh dari semiring dan near-ring, didefinisikan struktur aljabar baru yang disebut seminear-ring. Seminear-ring adalah himpunan tak kosong $S$ yang dilengkapi dengan operasi biner penjumlahan dan perkalian di mana $S$ terhadap operasi penjumlahan serta perkalian semigrup dan $S$ terhadap kedua operasi memenuhi hukum distributif kanan seperti 
pada near-ring (Kornthorng \& Iampan, 2012). Sehingga setiap near-ring merupakan seminearring tetapi belum tentu berlaku sebaliknya. Sebagai contoh pada himpunan semua bilangan asli $\mathbb{N}$ terhadap operasi penjumlahan dan perkalian merupakan seminear-ring tetapi $(\mathbb{N},+, \cdot)$ bukanlah near-ring sebab, $(\mathbb{N},+)$ bukan merupakan grup.

Konsep seminear-ring sendiri pertama kali diperkenalkan oleh Willy G. van Hoorn dan B. van Rootselar pada tahun 1967 dalam artikel (Van \& Van, 1967). Secara umum, seminearring merupakan hasil generalisasi dari semiring dan near-ring. Sehingga definisi ideal pada seminear-ring dapat didefinisikan dengan cara yang serupa dengan semiring dan near-ring. Beberapa hasil mengenai ideal pada seminear-ring telah diperoleh, yaitu (Hussain, Tahir, Abdullah, \& Sadiq, 2016) membahas tentang homomorfisma pada seminear-ring dan pembentukan seminear-ring kuosien. Paper (Perumal \& Chinnaraj, 2015)membahas tentang medial bipotent kiri pada seminear-ring, (Perumal, Arulprakasam, \& Radhakrishnan, 2018) membahas tentang beberapa definisi dan sifat-sifat ideal pada seminear-ring, (Ayaragarnchanakul \& Mitchell, 1994) membahas tentang division seminear-ring, ideal prima kuat pada seminear-ring telah dibahas oleh (Koppula, Srinivas, \& Prasad, 2020), serta ideal prima lemah pada seminear-ring telah dibahas di (Senthil \& Perumal, 2020). Dilain pihak, (Shabir \& Ahmed, 2007) telah membahas seminear-ring reguler lemah. Oleh karena itu, dalam tulisan kali ini akan dibahas beberapa perilaku ideal pada seminear-ring yaitu perilaku ideal pada seminear-ring, seperti ideal prima dan semiprima, $(A: B)$ sebagai ideal akan melibatkan hubungan $A$ dan $B$. Diidentifikasi pula himpunan $(A: B)$ sebagai ideal apabila $A$ merupakan ideal semiprima lengkap, annihilator kiri dan kanan sebagai ideal. Lebih lanjut, akan diidentifikasi bahwa apabila ideal kiri (kanan) $S a(a S)=S$ apakah $S$ merupakan seminear-ring sederhana kiri (kanan) serta jika $(S a) S=S$ maka $S$ juga merupakan seminear-ring sederhana.

Dalam tulisan ini permasalahan dibatasi pada pembahasan tentang konsep ideal pada seminear-ring, ideal prima, ideal semiprima pada seminear-ring serta seminear-ring sederhana. Selanjutnya, untuk dapat memahami sifat-sifat ideal, diberikan pula definisi insertion of ideals factors property menurut (Baek \& etc., 2014).

\section{B. Metodologi Penelitian}

Metode penelitian yang akan digunakan adalah studi literatur dengan langkah-langkah sebagai berikut.

1. Mempelajari artikel karya (Perumal, Arulprakasam, \& Radhakrishnan, 2018) dengan judul A Note on Ideals in Seminear-Rings. Artikel ini membahas tentang definisi serta sifat-sifat ideal pada seminear-ring diantaranya adalah ideal (ideal kanan dan ideal kiri), ideal prima, ideal semiprima, nil ideal, ideal semiprima lengkap, ideal prima lengkap, ideal prima tegas, serta ideal prima minimal pada seminear-ring.

2. Mempelajari sifat-sifat struktur seminear-ring yang telah dikaji sebelumnya melalui penelusuran literatur-literatur terkait. Seperti definisi dan sifat-sifat ideal lainnya pada seminear-ring yaitu $c$-ideal pada seminear-ring, annihilator kanan dan kiri pada seminear-ring, seminear-ring sederhana, dan sifat penyisipan faktor pada seminearring.

3. Mempelajari perilaku ideal kiri pada seminear-ring, perilaku sifat penyisipan faktor pada seminear-ring yang biasanya dapat ditemukan pada ring non-komutatif dan teori modul, serta hubungan antara seminear-ring dengan elemen nilpotent tak nol dengan sifat penyisipan faktor pada seminear-ring.

4. Mekonstruksi pembentukan ideal terkecil yang dapat dibangun oleh satu elemen dan sebuah subseminear-ring.

5. Merumuskan dan mengidentifikasi hubungan seminear-ring sederhana dengan ideal pada seminear-ring. 


\section{Hasil Penelitian dan Pembahasan}

Seminear-ring adalah himpunan tak kosong $S$ yang dilengkapi dengan operasi biner penjumlahan dan perkalian di mana $S$ terhadap operasi penjumlahan serta perkalian semigrup dan $S$ terhadap kedua operasi memenuhi hukum distributif kanan. Berikut diberikan sifat-sifat dari seminear-ring.

\section{Seminear-ring.}

Elemen nol pada seminear-ring disebut dengan elemen absorptif dan diberikan melalui definisi berikut.

Definisi 1.1. (Hussain, Tahir, Abdullah, \& Sadiq, 2016) Diberikan seminear-ring $(S,+, \cdot)$. Seminear-ring $S$ dikatakan memiliki elemen absorptif 0 apabila untuk setiap a $\in$ S memenuhi $0+a=a+0=a$ dan $a \cdot 0=0 \cdot a=0$.

Oleh karena sifat distributif pada seminear-ring $\mathbb{Z}$ terhadap operasi penjumlahan dan perkaliannya berlaku dua sisi yaitu sifat distributif kiri dan kanan. Sementara berdasarkan definisi seminear-ring diperoleh bahwa seminear-ring $(S,+, \cdot)$ cukup memenuhi salah satu sifat distributifnya, yaitu sifat distributif kanan. Hal ini memotivasi munculnya definisi seminearring distributif.

Definisi 1.2. (Hussain, Tahir, Abdullah, \& Sadiq, 2016) Diberikan seminearring $(S,+, \cdot)$. Elemen $a \in S$ disebut elemen distributif apabila untuk setiap $x, y \in$ $S$ berlaku $a(x+y)=a x+a y$.

Seminear-ring $S$ dikatakan distributif apabila $S$ memuat semua elemen distributif. Kemudian seperti halnya pada semiring dan near-ring yang memiliki definisi elemen nilpoten, begitu juga pada seminear-ring.

Definisi 1.3. (Hussain, Tahir, Abdullah, \& Sadiq, 2016) Diberikan seminearring $(S,+, \cdot)$. Elemen $a \in S$ disebut elemen nilpoten apabila terdapat bilangan bulat positif $k$ sedemikian sehingga $a^{k}=0$.

Definisi 1.4. (Hussain, Tahir, Abdullah, \& Sadiq, 2016) Diberikan seminear-ring $(S,+, \cdot)$. Elemen $a \in S$ disebut elemen idempoten apabila $a^{2}=a$.

Definisi 1.5. (Hussain, Tahir, Abdullah, \& Sadiq, 2016) Diberikan seminearring $(S,+, \cdot)$. Seminear-ring $S$ dikatakan memiliki sifat peyisipan faktor (IFP) apabila untuk setiap $a, b \in S, a b=0$ berakibat $a x b=0$, untuk setiap $x \in S$.

Lebih lanjut diberikan definisi dari seminear-ring $S$ yang dikatakan $(*, I F P)$.

Definisi 1.6. (Hussain, Tahir, Abdullah, \& Sadiq, 2016) Diberikan seminearring $(S,+, \cdot)$. Seminear-ring $S$ dikatakan $(*, I F P)$ apabila seminear-ring $S$ memiliki IFP dan untuk setiap $a, b \in R, a b=0$ maka $b a=0$.

Selanjutnya, seperti pada semiring yang memiliki subsemiring dan ideal pada semiring, subseminear-ring dan ideal pada seminear-ring didefinisikan dengan cara yang sama.

Definisi 1.7. (Perumal, Arulprakasam, \& Radhakrishnan, 2018) Diberikan seminear-ring $(S,+, \cdot), K \subseteq S$ dan $K \neq \emptyset$. Himpunan $K$ yang dikenakan operasi penjumlahan dan perkalian seperti pada $S$ disebut subseminear-ring apabila $K$ terhadap operasi penjumlahan dan perkaliannya merupakan seminear-ring. 
Definisi 1.8. (Hussain, Tahir, Abdullah, \& Sadiq, 2016) Diberikan seminearring $(S,+, \cdot)$ dan $I \subseteq S$. Himpunan tak kosong I disebut ideal kiri (kanan) pada seminear-ring $S$ apabila untuk setiap $x, y \in I, x+y \in I$ serta untuk setiap $x \in$ I dan $a \in R$, ax $\in I(x a \in I)$.

Ideal $I$ dikatakan ideal pada seminear-ring $S$ apabila $I$ ideal kanan sekaligus ideal kiri. Selanjutnya, seperti halnya ideal prima pada semiring, ideal prima pada seminear-ring didefinisikan dengan cara yang sama. Berikut diberikan definisinya.

Definisi 1.9. (Hussain, Tahir, Abdullah, \& Sadiq, 2016) Diberikan seminearring $(S,+, \cdot)$ dan I ideal. Ideal I disebut ideal prima apabila untuk setiap $A, B \subseteq$ $S$ ideal, $A B \subseteq I$ berakibat $A \subseteq I$ atau $B \subseteq I$.

Definisi 1.10. (Hussain, Tahir, Abdullah, \& Sadiq, 2016) Diberikan seminearring $(S,+, \cdot)$ dan I ideal. Ideal I disebut ideal semi prima apabila untuk setiap $A \subseteq S$ ideal, $A^{2} \subseteq I$ berakibat $A \subseteq I$

Selanjutnya, jika $I$ ideal prima di $S$ maka $I$ ideal semiprima di $S$.

Definisi 1.11. (Hussain, Tahir, Abdullah, \& Sadiq, 2016) Diberikan seminearring $(S,+, \cdot)$ dan I ideal. Ideal I disebut ideal semi prima lengkap apabila untuk setiap $x \in S, x^{2} \in I$ berakibat $x \in I$.

Definisi 1.12. (Hussain, Tahir, Abdullah, \& Sadiq, 2016) Diberikan seminearring $(S,+$,$) dan I ideal. Ideal I disebut ideal prima lengkap apabila untuk setiap$ $x, y \in S, x \in I$ berakibat $x \in I$ atau $y \in I$.

Lebih lanjut, jika $I$ ideal prima lengkap di $S$ maka $I$ ideal semiprima lengkap di $S$. Jika $I$ ideal semiprima lengkap di $S$ maka $I$ ideal semiprima di $S$. Kemudian, dengan $I$ ideal prima lengkap di $S$ maka $I$ ideal prima di $S$.

Definisi 1.13. (Hussain, Tahir, Abdullah, \& Sadiq, 2016) Diberikan seminearring $(S,+, \cdot)$ dan I ideal. Ideal I disebut ideal prima kuat apabila untuk setiap $A, B \subseteq S$ ideal kiri, $A B \subseteq I$ berakibat $A \subseteq I$ atau $B \subseteq I$.

Definisi 1.14. (Hussain, Tahir, Abdullah, \& Sadiq, 2016) Diberikan seminearring $(S,+, \cdot)$. Seminear-ring $S$ disebut seminear-ring prima apabila $\{0\}$ adalah ideal prima di $S$.

Definisi 1.15. (Hussain, Tahir, Abdullah, \& Sadiq, 2016) Diberikan seminearring $(S,+, \cdot)$. Seminear-ring $S$ disebut seminear-ring semiprima apabila $\{0\}$ adalah ideal semiprima di $S$.

Definisi 1.16. (Hussain, Tahir, Abdullah, \& Sadiq, 2016) Diberikan seminearring $(S,+, \cdot)$. Seminear-ring $S$ disebut seminear-ring prima kuat apabila $\{0\}$ adalah ideal prima kuat di $S$.

Diketahui bahwa elemen nilpoten pada seminear-ring $S$ yaitu $a^{n}=0$, untuk setiap $n \in$ $\mathbb{Z}^{+}$, sehingga ideal $I$ disebut nil apabila setiap elemen di $I$ elemen nilpoten. Lebih lanjut, seminear-ring $S$ disebut nil seminear-ring apabila setiap elemen di $S$ merupakan elemen nilpoten. 
Definisi 1.17. (Hussain, Tahir, Abdullah, \& Sadiq, 2016) Diberikan seminearring $(S,+, \cdot), A \subseteq S$ dan $A \neq \emptyset$. Annihilator kiri dari $A$ di $S$ adalah $\ell(A)=$ $\{x \in S \mid x a=0, \forall a \in A\}$ dan annihilator kanan dari $A$ di $S$ adalah $r(A)=$ $\{x \in S \mid a x=0, \forall a \in A\}$.

Apabila $A=\{a\}$ maka $\ell(A)$ dituliskan dengan $\ell(a)$ dan apabila $A=\{a\}$ maka $r(A)$ dituliskan dengan $r(a)$.

Definisi 1.18. (Hussain, Tahir, Abdullah, \& Sadiq, 2016) Diberikan seminearring $(S,+, \cdot), A, B \subseteq S$ dan $A, B \neq \emptyset$. Himpunan $(A: B)$ didefinisikan sebagai $\{x \in S \mid x B \subseteq A\}$.

Definisi 1.19. (Hussain, Tahir, Abdullah, \& Sadiq, 2016) Diberikan seminearring $(S,+, \cdot)$. Seminear-ring $S$ disebut seminear-ring sederhana kiri (kanan) apabila satu-satunya ideal kiri (kanan) tak nol di $S$ adalah $S$ itu sendiri.

Selanjutnya, $S$ disebut seminear-ring sederhana apabila $S$ tidak memiliki ideal non-trivial.

\section{Annihilator Seminear-ring sebagai Ideal di $S$.}

Proposisi 2.1. Diberikan seminear-ring $(S,+, \cdot)$. Jika $A \subseteq S$ dan $A \neq \emptyset$, maka $\ell(A)$ adalah ideal kiri dari $S$.

Bukti:

Akan ditunjukkan $\ell(A)$ ideal kiri di $S$. Diambil sebarang $a \in A$ dan $x, y \in \ell(A)$. Oleh karena $\ell(A) \subseteq S$ dan $S$ seminear-ring maka $(x+y) a=x a+y a=0+0=0$. Hal ini berakibat $x+$ $y \in \ell(A)$. Selanjutnya, diambil sebarang $a \in A, s \in S$ dan $x \in \ell(A)$. Oleh karena $\ell(A) \subseteq$ $S$ dan $S$ seminear-ring maka $(s x) a=s(x a)=s(0)=0$. Akibatnya $s x \in \ell(A)$, dengan demikian $\ell(A)$ adalah ideal kiri di $S$.

Selain annihilator kiri yang merupakan ideal kiri pada seminear-ring $S$, annihilator kanan juga merupakan ideal kanan pada seminear-ring distributif $S$. Namun, annihilator kanan belum tentu ideal kanan pada seminear-ring $S$.

Proposisi 2.2. Diberikan seminear-ring $(S,+, \cdot), A \subseteq S$ dan $A \neq \emptyset$. Jika $S$ seminear-ring distributif, maka $r(A)$ adalah ideal kanan dari $S$.

Bukti:

Akan ditunjukkan $r(A)$ ideal kanan di $S$. Diambil sebarang $a \in A$ dan $x, y \in r(A)$, artinya $a x=$ 0 dan $a y=0$. Oleh karena $r(A) \subseteq S$ dan $S$ seminear-ring distributif maka $a(x+y)=a x+$ $a y=0+0=0$. Hal ini berakibat $x+y \in r(A)$. Selanjutnya, diambil sebarang $a \in A, s \in S$ dan $x \in r(A)$ artinya $a x=0$. Oleh karena $r(A) \subseteq S$ dan $S$ seminear-ring distributif maka $a(x s)=(a x) s=(0) s=0$. Akibatnya $x s \in r(A)$, dengan demikian $r(A)$ adalah ideal kanan di seminear-ring distributif $S$.

Selanjutnya diberikan syarat perlu dan cukup suatu himpunan $I$ merupakan ideal kiri atau ideal kanan di $S$.

Proposisi 2.3. Diberikan seminear-ring $(S,+, \cdot)$ dan I subsemigrup $S$. Himpunan I disebut ideal kiri (kanan) di S jika dan hanya jika $S I \subseteq I(I S \subseteq I)$.

Bukti:

Akan ditunjukkan $S I \subseteq I(I S \subseteq I)$. Diambil sebarang si $\in S I$ (is $\in I S)$, dengan $s \in S$ dan $i \in I$. Oleh karena $I$ ideal kiri (kanan) di $S$, sehingga $s i(i s) \in I$. Dengan demikian terbukti bahwa 
$S I \subseteq I(I S \subseteq I)$. Selanjutnya, akan ditunjukkan $I$ ideal kiri (kanan) di $S$. Diambil sebarang $x, y \in I$ dan $s \in S$, karena $I$ subsemigrup di $S$ maka $x+y \in I$ dan karena $S I \subseteq I(I S \subseteq I)$ diperoleh $s x(x s) \in I$. Dengan demikian terbukti bahwa $I$ ideal kiri (kanan) di $S$.

Apabila seminear-ring $S$ memiliki sifat IFP, akan dianalisis perilaku annihilator kiri dari $A$ atau $\ell(A)$ di $S$. Lebih khusus, untuk setiap $s \in S$ annihilator kiri dari $S$ juga merupakan ideal di $S$.

Teorema 2.4. Diberikan seminear-ring $(S,+, \cdot)$. Pernyataan berikut ekuivalen:

a. Seminear-ring $\boldsymbol{S}$ memiliki sifat IFP.

b. Untuk setiap $\boldsymbol{S} \in \boldsymbol{S}, \boldsymbol{\ell}(\boldsymbol{S})$ ideal di $\boldsymbol{S}$.

c. Untuk setiap himpunan $\boldsymbol{A} \subseteq \boldsymbol{S}, \boldsymbol{\ell}(\boldsymbol{A})$ ideal di $\boldsymbol{S}$.

Bukti:

$(a \rightarrow b)$ Akan ditunjukkan untuk setiap $s \in S, \ell(S)$ ideal di $S$. Berdasarkan Proposisi 2.1. diperoleh bahwa untuk sebarang seminear-ring $S, \ell(S)$ ideal kiri di $S$. Tinggal ditunjukkan bahwa $\ell(S)$ ideal kanan di $S$. Diambil sebarang $p \in S$ dan $x, y \in \ell(S)$, artinya untuk setiap $s \in$ $S, x s=0$ dan $y s=0$. Perhatikan bahwa $(x+y) s=x s+y s=0+0=0$. Hal ini berakibat $x+y \in \ell(S)$. Selanjutnya, karena $S$ memiliki sifat IFP dan untuk setiap $x \in \ell(S), x S=0$ maka $(x p) s=0$ berakibat $x p \in \ell(S)$. Dengan demikian diperoleh bahwa $\ell(S)$ ideal kanan di $S$. Oleh karena $\ell(S)$ juga merupakan ideal kiri di $S$. Jadi terbukti bahwa $\ell(S)$ ideal di $S$.

$(b \rightarrow c)$ Akan ditunjukkan untuk setiap himpunan $A \subseteq S, \ell(A)$ ideal di $S$. Berdasarkan Proposisi 2.1 diperoleh bahwa untuk sebarang seminear-ring $S, \ell(A)$ ideal kiri di $S$. Tinggal ditunjukkan bahwa $\ell(A)$ ideal kanan di $S$. Diambil sebarang $p \in S$ dan $x, y \in \ell(A)$, artinya untuk setiap $a \in A, x a=0$ dan $y a=0$. Perhatikan bahwa $(x+y) a=x a+y a=0+0=0$. Hal ini berakibat $x+y \in \ell(A)$. Selanjutnya, karena $S$ memiliki sifat IFP dan untuk setiap $x \in$ $\ell(A), x a=0$ maka $(x p) a=0$ berakibat $x p \in \ell(A)$. Dengan demikian diperoleh bahwa $\ell(A)$ ideal kanan di $S$. Oleh karena $\ell(A)$ juga merupakan ideal kiri di $S$. Jadi terbukti bahwa $\ell(A)$ ideal di $S$.

$(c \rightarrow a)$ Akan ditunjukkan seminear-ring $S$ memiliki sifat IFP. Diambil sebarang $a, b \in S$ dengan $a b=0$, artinya $a \in \ell(b)$. Berdasarkan (iii) diperoleh bahwa untuk setiap $b \in S, \ell(b)$ ideal di $S$. Hal ini berakibat untuk setiap $s \in S$ berlaku $a s \in \ell(b)$ yang artinya $(a s) b=0, \forall s \in$ $S$. Dengan demikian seminear-ring $S$ dapat dikatakan memiliki sifat IFP.

Selanjutnya, diberikan syarat cukup annihilator kiri dari $A$ di $S$ merupakan ideal pada $S$. Namun, ditunjukkan dahulu bahwa $S$ merupakan seminear-ring yang memiliki $(*, I F P)$ apabila $S$ merupakan seminear-ring tanpa elemen nilpoten tak nol.

Proposisi 2.5. Diberikan seminear-ring $(S,+, \cdot)$. Jika seminear-ring $S$ adalah seminear-ring tanpa elemen nilpoten tak nol, maka $S$ memiliki $(*, I F P)$.

Bukti:

Akan ditunjukkan bahwa $S$ memiliki $(*, I F P)$. Diambil sebarang $x, y \in S$ dengan $x y=0$, karena $S$ seminear-ring maka $(y x)^{2}=(y x)(y x)=y(x y) x=y 0 x=0$. Oleh karena $S$ merupakan seminear-ring tanpa elemen nilpoten yang tak nol, maka $y x=0$. Selanjutnya untuk setiap $a \in S$ diperoleh $(x a y)^{2}=(x a y)(x a y)=x a(y x) a y=x a 0 a y=0$. Dengan demikian diperoleh bahwa $x a y=0, \forall a \in S$. Dengan kata lain terbukti bahwa $S$ memiliki $(*, I F P)$.

Proposisi 2.6. Diberikan seminear-ring $(S,+, \cdot), A \neq \emptyset$. Jika seminear-ring $S$ adalah seminear-ring tanpa elemen nilpoten tak nol, maka $\ell(A)$ adalah ideal dari $S$, untuk setiap $A \subseteq S$.

Bukti: 
Akan ditunjukkan bahwa $\ell(A)$ ideal dari $S$, untuk setiap $A \neq \emptyset \subseteq S$. Berdasarkan Preposisi 4.1. telah diperoleh bahwa untuk sebarang seminear-ring $S, \ell(A)$ ideal kiri di $S$ dengan $S$ seminearring tanpa elemen nilpoten tak nol. Tinggal ditunjukkan bahwa $\ell(A)$ ideal kanan di $S$ seminearring tanpa elemen nilpoten tak nol. Diambil sebarang $s \in S$ dan $x, y \in \ell(A)$, artinya $x a=0$ dan $y a=0$, untuk setiap $a \in A$. Perhatikan bahwa $(x+y) a=x a+y a=0+0=0$, berakibat $x+y \in \ell(A)$. Selanjutnya karena $S$ seminear-ring tanpa elemen nilpoten tak nol, dengan $(a x)^{2}=(a x)(a x)=a(x a) x=a 0 x=0$ diperoleh $a x=0$, sehingga $((x s) a)^{2}=$ $((x s) a)((x s) a)=(x s a)(x s a)=x s(a x) s a=x s 0 s a=0 . \quad$ Dengan demikian diperoleh $(x S) a=0$ atau $x s \in \ell(A)$ atau $\ell(A)$ ideal kanan di $S$. Oleh karena $\ell(A)$ ideal kanan dan ideal kiri di $S$. Terbukti bahwa $\ell(A)$ ideal di seminear-ring tanpa elemen nilpoten tak nol $S$.

\section{Ideal $(A: B)$ pada Seminear-ring $S$.}

Pada seminear-ring $S$ telah didefinisikan himpunan $(A: B)$ dengan $A, B \subseteq S$. Selanjutnya, diberikan syarat cukup himpunan $(A: B)$ di $S$ merupakan ideal kiri.

Proposisi 3.1. Diberikan seminear-ring $(S,+, \cdot), A \subseteq S$. Jika A ideal di $S$ dan $B \subseteq S$, maka $(A: B)$ merupakan ideal kiri di $S$.

Bukti:

Akan ditunjukkan $(A: B)$ merupakan ideal kiri di $S$. Diambil sebarang $s \in S$ dan $x, y \in(A: B)$ artinya $x B \subseteq A$ dan $y B \subseteq A$. Perhatikan bahwa $(x+y) B=x B+y B$. Oleh karena $A$ ideal di $S$ dan $x B \subseteq A$ serta $y B \subseteq A$, maka $(x+y) B \subseteq A$. Dengan kata lain $x+y \in(A: B)$. Selanjutnya, $(s x) B=s(x B)$ dengan alasan yang sama diperoleh bahwa $s x \in(A: B)$. Dengan demikian terbukti bahwa $(A: B)$ ideal kiri di $S$.

Lebih lanjut, untuk $A$ dan $A$ ideal di $S$, himpunan $(A: B)$ merupakan sebuah ideal di $S$.

Proposisi 3.2. Diberikan seminear-ring $(S,+, \cdot), A, B \subseteq S$. Jika A dan B ideal di $S$, maka $(A: B)$ merupakan ideal di $S$.

Bukti:

Akan ditunjukkan $(A: B)$ merupakan ideal di $S$. Diambil sebarang $s \in S$ dan $x, y \in(A: B)$ artinya $x B \subseteq A$ dan $y B \subseteq A$. Perhatikan bahwa $(x+y) B=x B+y B$. Oleh karena $A$ ideal di $S$ dan $x B \subseteq A$ serta $y B \subseteq A$, maka $(x+y) B \subseteq A$. Dengan kata lain $x+y \in(A: B)$. Selanjutnya, $(s x) B=s(x B)$ karena $A$ ideal di $S$ dan $x B \subseteq A$ diperoleh bahwa $s x B \subseteq A$ sehingga $s x \in(A: B)$. Dilain pihak $(x s) B=x(s B)$, karena $B$ ideal di $S$ dan $s B \subseteq B$ serta $x(s B) \subseteq x B \subseteq A$. Hal ini berakibat $x s B \subseteq A$ sehingga $x s \in(A: B)$. Dengan demikian diperoleh bahwa $(A: B)$ ideal di $S$.

Apabila $A$ diperkuat menjadi suatu ideal semiprima lengkap, akan diperoleh $(A: B)$ merupakan ideal pada $S$.

Proposisi 3.3. Diberikan seminear-ring $(S,+, \cdot), I \subseteq S$ ideal semiprima lengkap. Jika A sebarang subset di S, maka (I: A) merupakan ideal di $S$.

Bukti:

Akan ditunjukkan bahwa ( $I: A)$ merupakan ideal di $S$ dengan $I$ adalah ideal semiprima lengkap dan $A \subseteq S$. Diambil sebarang $x, y \in(I: A)$ artinya $x \in x A \subseteq I$ dan $y \in y A \subseteq I$. Perhatikan bahwa $(x+y) A=x A+y A$, karena $x A, y A \subseteq I$ dan $I$ ideal semiprima lengkap di $S$, maka $(x+y) A \subseteq I$. Hal ini berakibat $x+y \in(I: A)$. Selanjutnya untuk sebarang $x \in(I: A)$ artinya $x=x a \in x A \subseteq I$ dan karena $I$ ideal maka, $(a x)^{2}=(a x)(a x)=a(x a) x \subseteq S I S \subseteq S I \subseteq I$. Oleh karena $I$ ideal semiprima lengkap maka $a x \in I$. Sehingga untuk sebarang $s \in S$ diperoleh $s x a \in s I \subseteq I$. Dengan demikian $s x \in I$ atau $I$ merupakan ideal kiri di $S$. Selanjutnya untuk 
setiap $r \in S$ berlaku $(x r a)^{2}=(x r a)(x r a)=x r(a x) r a \subseteq S I S \subseteq S I \subseteq S$. Sehingga diperoleh bahwa $x r \in I$ atau $I$ merupakan ideal kanan di $S$. Jadi, terbukti bahwa $I$ merupakan ideal di $S$.

\section{Seminear-ring Sederhana.}

Selanjutnya, akan diketahui pembentukan seminear-ring sederhana melalui $S a$ dan $a S$ sebagai ideal kiri dan ideal kanan di $S$, dengan definisi untuk setiap $a \in S, a S(S a)$ dinotasikan sebagai himpunan semua jumlahan berhingga di mana $\Sigma a x_{k}\left(\Sigma x_{k} a\right)$. Oleh karena $S$ memenuhi hukum distributif kanan, sehingga $S a=\{x a \mid x \in S\}$.

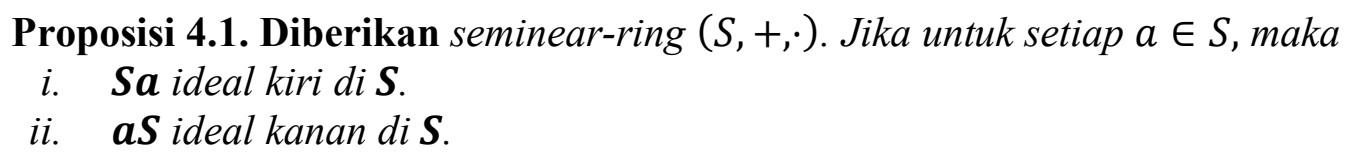

Bukti:

i. Akan ditunjukkan Sa ideal kiri di S. Diambil sebarang $\mathbf{x}, \mathbf{y} \in \mathbf{S a}$, artinya $\mathbf{x}=\mathbf{s a}$ dan $\mathbf{y}=$ ra dengan $\mathbf{s}, \mathbf{r} \in \mathbf{S}$. Perhatikan bahwa $\mathbf{x}+\mathbf{y}=\mathbf{s a}+\mathbf{r a}=(\mathbf{s}+\mathbf{r}) \mathbf{a}$. Oleh karena $\mathbf{s}, \mathbf{r} \in \mathbf{S}$ dan $\mathbf{S}$ seminear-ring, maka $\mathbf{s}+\mathbf{r} \in \mathbf{S}$. Akibatnya $\mathbf{x}+\mathbf{y} \in \mathbf{S a}$. Selanjutnya untuk setiap $\mathbf{p} \in \mathbf{S}$ berlaku $\mathbf{p x}=\mathbf{p}(\mathbf{s a})=(\mathbf{p s}) \mathbf{a}$. Oleh karena $\mathbf{p s} \in \mathbf{S}$, akibatnya $\mathbf{p x} \in \mathbf{S a}$. Dengan demikian terbukti bahwa Sa ideal kiri di $\mathbf{S}$.

ii. Akan ditunjukkan aS ideal kanan di S. Diambil sebarang $\mathbf{x}, \mathbf{y} \in \mathbf{a S}$, artinya $\mathbf{x}=\mathbf{\Sigma} \mathbf{a s}_{\mathbf{i}}$ dan $\mathbf{y}=\boldsymbol{\Sigma} \boldsymbol{a r}_{\mathbf{i}}$ dengan $\boldsymbol{s}_{\mathrm{i}}, \mathbf{r}_{\mathbf{i}} \in \mathbf{S}, \forall \mathbf{i}$. Perhatikan bahwa $\boldsymbol{x}+\boldsymbol{y}=\boldsymbol{\Sigma} \boldsymbol{a} \boldsymbol{s}_{\boldsymbol{i}}+\boldsymbol{\Sigma} \boldsymbol{a} \boldsymbol{r}_{\boldsymbol{i}}=\boldsymbol{\Sigma}\left(\boldsymbol{a s _ { i }}+\boldsymbol{a r _ { i }}\right)=$ $\boldsymbol{\Sigma} \boldsymbol{a}\left(\boldsymbol{s}_{\boldsymbol{i}}+\boldsymbol{r}_{\boldsymbol{i}}\right)=\boldsymbol{a} \boldsymbol{\Sigma}\left(\boldsymbol{s}_{\boldsymbol{i}}+\boldsymbol{r}_{\boldsymbol{i}}\right)$. Oleh karena $\boldsymbol{s}_{\boldsymbol{i}}, \boldsymbol{r}_{\boldsymbol{i}} \in \boldsymbol{S}$ dan $\boldsymbol{S}$ seminear-ring, maka $\boldsymbol{s}_{\boldsymbol{i}}+\boldsymbol{r}_{\boldsymbol{i}} \in$ $\boldsymbol{S}, \forall \boldsymbol{i}$, lebih lanjut $\boldsymbol{\Sigma}\left(\boldsymbol{s}_{\boldsymbol{i}}+\boldsymbol{r}_{\boldsymbol{i}}\right) \in \boldsymbol{S}$. Akibatnya $\boldsymbol{x}+\boldsymbol{y} \in \boldsymbol{a} \boldsymbol{S}$. Selanjutnya untuk setiap $\boldsymbol{p} \in \boldsymbol{S}$ berlaku $\boldsymbol{x p}=\left(\boldsymbol{\Sigma} \boldsymbol{a} \boldsymbol{s}_{\boldsymbol{i}}\right) \boldsymbol{p}=\boldsymbol{\Sigma} \boldsymbol{a} \boldsymbol{s}_{\boldsymbol{i}} \boldsymbol{p}=\boldsymbol{a} \boldsymbol{\Sigma} \boldsymbol{s}_{\mathrm{i}} \boldsymbol{p}$. Oleh karena $\boldsymbol{s}_{\boldsymbol{i}} \boldsymbol{p} \in \boldsymbol{S}, \forall \boldsymbol{i}$, dan $\boldsymbol{\Sigma} \boldsymbol{s}_{\boldsymbol{i}} \boldsymbol{p} \in \boldsymbol{S}$. Akibatnya $\boldsymbol{x p} \in \boldsymbol{a} \boldsymbol{S}$. Dengan demikian terbukti bahwa $\boldsymbol{a} \boldsymbol{S}$ ideal kanan di $\boldsymbol{S}$.

Selanjutnya, akan diidentifikasi $S a^{2}$ dan $a^{2} S$ sebagai ideal kiri dan kanan berturut-turut di $S$. Definisi $S a^{2}=\left\{x a^{2} \mid x \in S\right\}$ dan $a^{2} S=\left\{\sum a^{2} x \mid x \in S\right\}$.

Proposisi 4.2. Diberikan seminear-ring $(S,+, \cdot)$. Jika untuk setiap a $\in S$, maka:

i. $\quad \boldsymbol{S a}^{2}$ ideal kiri di $\boldsymbol{S}$.

ii. $\quad \boldsymbol{a}^{2} \boldsymbol{S}$ ideal kanan di $\boldsymbol{S}$.

Bukti:

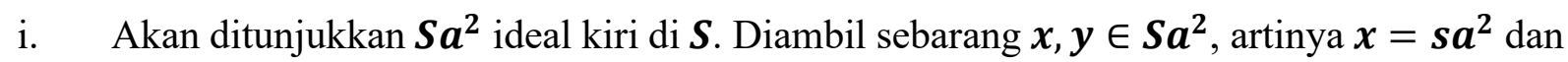
$\boldsymbol{y}=\boldsymbol{r} \boldsymbol{a}^{2}$ dengan $s, r \in S$. Perhatikan bahwa $x+y=s \boldsymbol{a}^{2}+r \boldsymbol{a}^{2}=(s+r) \boldsymbol{a}^{2}$. Oleh karena $\boldsymbol{s}, \boldsymbol{r} \in \boldsymbol{S}$ dan $\boldsymbol{S}$ seminear-ring, maka $\boldsymbol{s}+\boldsymbol{r} \in \boldsymbol{S}$. Akibatnya $\boldsymbol{x}+\boldsymbol{y} \in \boldsymbol{S} \boldsymbol{a}^{2}$. Selanjutnya untuk setiap $\boldsymbol{p} \in \boldsymbol{S}$ berlaku $\boldsymbol{p} \boldsymbol{x}=\boldsymbol{p}\left(\boldsymbol{s} \boldsymbol{a}^{2}\right)=(\boldsymbol{p s}) \boldsymbol{a}^{2}$. Oleh karena $\boldsymbol{p s} \in \boldsymbol{S}$, akibatnya $\boldsymbol{p} \boldsymbol{x} \in \boldsymbol{S} \boldsymbol{a}$. Dengan demikian terbukti bahwa $\boldsymbol{S a}$ ideal kiri di $\boldsymbol{S}$.

ii. Akan ditunjukkan $\boldsymbol{a}^{2} \boldsymbol{S}$ ideal kanan di $\boldsymbol{S}$. Diambil sebarang $\boldsymbol{x}, \boldsymbol{y} \in \boldsymbol{a}^{2} \boldsymbol{S}$, artinya $\boldsymbol{x}=\boldsymbol{\Sigma} \boldsymbol{a}^{2} \boldsymbol{s}_{\boldsymbol{i}}$ dan $\boldsymbol{y}=\boldsymbol{\Sigma} \boldsymbol{a}^{2} \boldsymbol{r}_{\boldsymbol{i}}$ dengan $\boldsymbol{s}_{\boldsymbol{i}}, \boldsymbol{r}_{\boldsymbol{i}} \in \boldsymbol{S}, \forall \boldsymbol{i}$. Perhatikan bahwa $\boldsymbol{x}+\boldsymbol{y}=\boldsymbol{\Sigma} \boldsymbol{a}^{\mathbf{2}} \boldsymbol{s}_{\boldsymbol{i}}+\boldsymbol{\Sigma} \boldsymbol{a}^{2} \boldsymbol{r}_{\boldsymbol{i}}=$ $\Sigma\left(a^{2} s_{i}+a^{2} r_{i}\right)=\Sigma a^{2}\left(s_{i}+r_{i}\right)=a^{2} \Sigma\left(s_{i}+r_{i}\right)$. Oleh karena $s_{i}, r_{i} \in S$ dan $S$ seminearring, maka $\boldsymbol{s}_{\boldsymbol{i}}+\boldsymbol{r}_{\boldsymbol{i}} \in \boldsymbol{S}, \forall \boldsymbol{i}$, lebih lanjut $\boldsymbol{\Sigma}\left(\boldsymbol{s}_{\boldsymbol{i}}+\boldsymbol{r}_{\boldsymbol{i}}\right) \in \boldsymbol{S}$. Akibatnya $\boldsymbol{x}+\boldsymbol{y} \in \boldsymbol{a}^{2} \boldsymbol{S}$. Selanjutnya untuk setiap $p \in S$ berlaku $x p=\left(\Sigma a^{2} s_{i}\right) p=\Sigma a^{2} s_{i} p=a^{2} \Sigma s_{i} p$. Oleh karena $\boldsymbol{s}_{\boldsymbol{i}} \boldsymbol{p} \in \boldsymbol{S}, \forall \boldsymbol{i}$, dan $\boldsymbol{\Sigma} \boldsymbol{s}_{\boldsymbol{i}} \boldsymbol{p} \in \boldsymbol{S}$. Akibatnya $\boldsymbol{x p} \in \boldsymbol{a}^{2} \boldsymbol{S}$. Dengan demikian terbukti bahwa $\boldsymbol{a}^{2} \boldsymbol{S}$ ideal kanan di $\boldsymbol{S}$.

Selanjutnya, akan ditunjukkan bahwa $a S$ dan $S a$ merupakan satu-satunya ideal kanan dan kiri di seminear-ring $S$, sehingga $S$ membentuk seminear-ring sederhana kiri dan kanan.

Proposisi 4.3. Diberikan seminear-ring $(S,+, \cdot)$. Jika untuk setiap a $\in S, S a=$ $S$ maka $S$ adalah seminear-ring sederhana kiri. 
Bukti:

Akan ditunjukkan $S$ seminear-ring sederhana kiri. Andaikan ada ideal kiri yang lain yaitu $I$ dengan $S \neq I$, maka untuk setiap $i \in I \subseteq S$ diperoleh $S=S i \subseteq S I \subseteq I$. Oleh karena $I \subseteq S$ dan $S \subseteq I$, didapat $S=I$. Kontradiksi dari yang diketahui bahwa $S \neq I$, sehingga pengandaian salah haruslah tidak ada ideal kiri yang lain selain $S=S a$.

Proposisi 4.4. Diberikan seminear-ring $(S,+, \cdot)$. Jika untuk setiap a $\in S$, aS $=$ $S$ jika dan hanya jika $S$ adalah seminear-ring sederhana kanan.

Bukti:

Akan ditunjukkan $S$ seminear-ring sederhana kanan. Andaikan ada ideal kanan yang lain yaitu $I$ dengan $S \neq I$, maka untuk setiap $i \in I \subseteq S$ diperoleh $S=i S \subseteq I S \subseteq I$. Oleh karena $I \subseteq S$ dan $S \subseteq I$, didapat $S=I$. Kontradiksi dari yang diketahui bahwa $S \neq I$, sehingga pengandaian salah haruslah tidak ada ideal kanan yang lain selain $S=a S$. Sebaliknya, akan ditunjukkan bahwa $S=a S$. Berdasarkan Proposisi 4.36. diketahui bahwa $a S$ merupakan ideal kanan di $S$. Karena $S$ adalah seminear-ring sederhana kanan, maka diperoleh bahwa $S=a S$.

Lebih lanjut, akan diidentifikasi seminear-ring sederhana.

Proposisi 4.4. Diberikan seminear-ring $(S,+, \cdot)$. Jika untuk setiap $a \in S$, $(S a) S=S$ maka $S$ adalah seminear-ring sederhana.

Bukti:

Akan ditunjukkan $S$ seminear-ring sederhana. Andaikan ada ideal yang lain yaitu $I$ dengan $S \neq$ $I$, maka untuk setiap $i \in I \subseteq S$ diperoleh $S=S i S \subseteq S I S \subseteq I S \subseteq I$. Oleh karena $I \subseteq S$ dan $S \subseteq$ $I$, didapat $S=I$. Kontradiksi dari yang diketahui bahwa $S \neq I$, sehingga pengandaian salah haruslah tidak ada ideal yang lain selain $S=S a S$.

\section{Kesimpulan}

Annihilator kiri dari seminear-ring $S$ merupakan ideal kiri di $S$, tetapi belum tentu berlaku sebaliknya. Dilain pihak, Annihilator kanan dari seminear-ring distributif $S$ juga merupakan ideal kanan di $S$. Syarat perlu dan syarat cukup annihilator kiri disebut ideal di seminear-ring $S$, apabila $S$ merupakan seminear-ring yang memiliki sifat penyisipan faktor (IFP). Selain itu, apabila $S$ merupakan seminear-ring dengan elemen nilpotent tak nol dan memiliki sifat $(*, I F P)$ diperoleh syarat perlu dan cukup untuk annihilator kiri membentuk ideal pada seminear-ring $S$.

Himpunan $(A: B)$ juga merupakan ideal pada seminear-ring, jika $A$ ideal pada seminearring $S$, maka $(A: B)$ hanya merupakan ideal kiri pada $S$. Namun, jika $A$ ideal serta $B$ ideal diperoleh $(A: B)$ ideal di $S$. Selanjutnya, apabila $A$ merupakan ideal semiprima lengkap diperoleh bahwa $(A: B)$ ideal di $S$.

Himpunan $S a$ dan $a S$ yang ada pada semiring komutatif merupakan ideal. Namun, dalam seminear-ring diperoleh bahwa $S a$ merupakan ideal kiri di $S$ dan $a S$ merupakan ideal kanan di $S$. Hal ini dipengaruhi oleh tidak berlakunya sifat komutatif terhadap operasi perkalian pada seminear-ring $S$. Namun, hasil yang dapat diperoleh dari $S a$ dan $a S$ adalah keduanya dapat mengkonstruksi seminear-ring sederhana kiri dan seminear-ring sederhana kanan. Lebih lanjut, apabila $(S a) S=S$ maka $S$ merupakan seminear-ring sederhana. 


\section{DAFTAR PUSTAKA}

Atani, R. E. (2013). Generalizations of Prime Ideals of Semirings. Azerbaijan Journal of Mathematics,3(1) 76-83. Retrieved from: https://www.azjm.org.

Ayaragarnchanakul, J., \& Mitchell, S. (1994). Division Seminear-rings. Kyungpook Mathematical Journal, 34(1)67-72. Retrieved From: https://www.koreascience.or.kr

Baek, S. H., \& etc. (2014). Insertion-Of-Ideal-Factors-Property. East Asian Math Journal, 30(5) 617-623. Retrieved From: https://doi.org/10.7858/eamj.2014.041

Dummit, D. S., \& Foote, R. M. (2004). Abstract Algebra third edition. United States of America: John Wiley and Sons, Inc.

Golan, J. S. (2013). Semirings and Affine Equations over Them: Theory and Applications. Amsterdam: Kluwer Academic Publishers.

Hussain, F., Tahir, M., Abdullah, S., \& Sadiq, N. (2016). Quotient Seminear-Rings. Indian Journal of Science and Technology, 9(38)1-7. doi:10.17485/ijst/2016/v9i38/89115

Koppula, K., Srinivas, K. B., \& Prasad, K. S. (2020). On Prime Strong Ideals of a Seminearring. Matematicki Vesnik, 72(3)243-256. Retrieved From: https://manipal.pure.elsevier.com/en/publications/on-prime-strong-ideals-of-aseminearring

Kornthorng, N., \& Iampan, A. (2012). A Note on Right Full k-Ideals of Seminearrings. Journal of Informatics and Mathematical Sciences, 4(3)255-261. Retrieved From: https://www.research.science.up.ac.th

Malik, D., Mordeson, J. S., \& Sen, M. (1997). Fundamentals of Abstract Algebra. United States of America: The Mc Graw-Hill Companies, Inc.

Perumal, R., Arulprakasam, R., \& Radhakrishnan, M. (2018). A note on Ideals in SeminearRings. National Conference on Mathematical Techniques and Its Applications, 1000(1)1-6. doi: 10.1088/1742-6596/1000/1/012150

Perumal, R., \& Chinnaraj, P. (2015). Medial Left Bipotent Seminear-Rings. Springer Proceedings in Mathematics and Statistics, 139(1)451-457. Retrieved From: https://doi.org/10.1007/978-81-322-2452-5_31

Pilz, G. (1983). Near-Rings. Amsterdam: North-Holland Publishing Company.

Senthil, S., \& Perumal, R. (2020). Minimal Prime Ideals in Seminearrings. Journal of Physics: Conference Series, 1-4. doi:10.1088/1742-6596/1850/1/012100

Shabir, M., \& Ahmed, I. (2007). Weakly Regular Seminearrings. International Electronic Journal of Algebra, 2(2)114-126. Retrieved From: https://dergipark.org.tr/en/pub/ieja/issue/25209/266403 
Van, H. W., \& Van, R. B. (1967). Fundamental Notions In The Theory Of Seminearrings. Compositio Mathematica, $18(1) 65-78$.

Retrieved from: http://www.numdam.org/item?id=CM_1967_18_1-2_65_0 